DOI:10.2478/rrlm-2020-0019

\title{
Bone status and aortic calcifications in chondrocalcinosis patients
}

\author{
Paulina Vele ${ }^{*}$, Ciprian Nicolae Silaghi ${ }^{2}$, Laura Otilia Damian ${ }^{3}$, Siao-Pin Simon ${ }^{1}$, \\ Alexandra Craciun ${ }^{2}$, Simona Rednic ${ }^{1}$ \\ 1. Department of Rheumatology, University of Medicine and Pharmacy \\ "Iuliu Hatieganu”, Cluj Napoca, Romania \\ 2. Department of Medical Biochemistry, University of Medicine and Pharmacy \\ “Iuliu Hatieganu”, Cluj Napoca, Romania \\ 3. Department of Rheumatology, Emergency County Teaching Hospital, \\ Cluj-Napoca, Romania
}

\begin{abstract}
Aim: We aimed to examine the association between several circulating bone turnover markers [ osteocalcin (OC), osteoprotegerin (OPG), beta-CrossLaps ( $\beta$-CTx)], hip and spine bone mineral density (BMD) and abdominal aortic calcification (AAC) in patients with chondrocalcinosis (CC). Methods: Thirty-six patients with CC and thirty-seven controls were consecutively enrolled in this pilot case-control, cross-sectional study. The following parameters were assessed: serum levels of OC, $O P G$ and $\beta$-CTx by enzyme-linked immunosorbent assay (ELISA); hip and spine BMD by dual-energy $X$-ray absorptiometry and AAC score by lateral radiography. Results: Patients with CC had higher levels of serum bone turnover markers and AAC score than the control group: OC [6.5 (3.5-9.9) vs 4.5 (2.6-7.2) ng/ml; $p=0.05], O P G ~[(7.7$ (6.2-9.4) vs 6.5 (5.5-8.12) $\mathrm{pmol} / \mathrm{ml} ; \mathrm{p}=0.02], \beta$-CTx [6078 (5870-

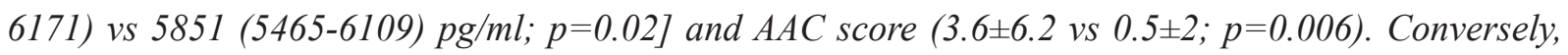
even if statistical significance was not reached, hip and spine BMD was lower in patients with $C C$. Additionally, we found a positive correlation between OPG and AAC, but also between OPG and osteoporosis in patients with $C C$. Conclusion: Patients with $C C$ are characterized by higher circulating $O C$, $O P G$ and $\beta$-CTx. The presence of AAC was more common in patients with $C C$, being only associated with serum $O P G$.
\end{abstract}

Keywords: chondrocalcinosis, osteocalcin, osteoprotegerin, beta cross laps, abdominal aortic calcifications

Received: 25 $5^{\text {th }}$ November 2019; Accepted: $19^{\text {th }}$ February 2020; Published: $5^{\text {th }}$ March 2020

*Corresponding author: Paulina Vele, Department of Rheumatology, "Iuliu Hatieganu" University of Medicine and Pharmacy, Cluj Napoca, Romania. E-mail: paulina.vele@yahoo.com 


\section{Introduction}

Chondrocalcinosis (CC), defined as cartilage and fibrocartilage calcification identified by imaging or histological examination, is caused mainly by the deposition of calcium pyrophosphate (CPP) crystals in the cartilage of joints $(1,2)$. The diagnosis of $\mathrm{CC}$ is confirmed either by radiography as the presence of a thin line, parallel with the articular surface and/or punctiform fibrocartilage calcification, or by ultrasound according to Frediani's ultrasound (US) patterns $(3,4)$.

Impaired inorganic pyrophosphate (PPi) levels are essential for the occurrence of CC. The formation of CPP crystals commences with excess extracellular PPi, which inhibits the basic calcium phosphate $(\mathrm{BCP})$ crystal formation. Conversely, reduced extracellular PPi promotes $\mathrm{BCP}$ crystal formation (5).

Bone status alterations and articular and vascular calcifications accompany the aging process and are associated with high morbidity and mortality. The clinical significance is the association and worsening of osteoarthritis in patients with articular calcifications and increased cardiovascular risk in patients with vascular calcifications and low bone mass (6-9).

In the past years, more data show that these pathological processes may share common pathways beyond the aging process $(5,10-17)$. The main link between the three pathological processes - articular calcifications, arterial calcifications, and bone mineralization - is probably caused by PPi dysregulation in the vascular smooth muscle cell (VSMC) and the osteocyte/ osteoblast (5). Also, more complex mechanisms are implicated (5, 10-21). Moreover, another reason to study the bone status in $\mathrm{CC}$ is the proven association with osteoarthritis, which can modify the bone mineral density (BMD) due to generalized or local alteration of the bone $(22,23)$. Therefore, the aim of this study was to investi- gate the association between osteocalcin (OC) as a marker of bone formation, osteoprotegerin $(\mathrm{OPG})$ as a regulator of bone metabolism, Beta CrossLaps ( $\beta$-CTx) as a marker of bone resorption, abdominal aortic calcification (AAC) and $\mathrm{BMD}$ in patients with $\mathrm{CC}$.

\section{Methods}

\section{Patients}

We performed a cross-sectional study by consecutively enrolling patients diagnosed with $\mathrm{CC}$ and controls. Signed informed consent was obtained from every subject, and the study was approved by the Ethics Committee of the University.

The CC group included patients with knee swelling and/or pain, as well as radiographic and ultrasonographic evidence of $\mathrm{CC}$ at least in the knee joint. Nineteen patients also fulfilled the McCarty criteria for calcium pyrophosphate deposition (CPPD) disease (1).

The radiographic evidence of $\mathrm{CC}$ was considered to be a thin line, parallel with the subchondral bone in the middle zone of the cartilage (hyaline cartilage calcification) and punctate, dense as fibrocartilage calcification in the knees (3). The radiographs were made in a posteroanterior, weight-bearing semi-flexed position in all patients. The radiographs were not obtained with the same radiologic equipment, but the radiographs were interpreted by the same examiner.

Ultrasonographic evidence of CC was considered to be calcific deposition on cartilage and fibrocartilage, according to Frediani's US patterns (4). US examinations were performed by the same examiner using an Esaote MyLab 25 Gold with 5-10 and 10-18 MHz linear probes. The synovial fluid analysis was performed using polarized light microscopy. CPP crystals were considered to be those with a parallelepipedic or rhomboid shape and weak birefringence (24). 
Exclusion criteria were gout and/or other inflammatory rheumatic diseases. Patients with oral anticoagulant, renal impairment, or a medication known to interfere with bone metabolism or anti-osteoporosis therapy (bisphosphonates) were also excluded from both groups.

The control group included age- and gender-matched patients presenting with mechanical pain (pain that worsens with activity and improves with rest, short-term joint stiffness) with an indication for radiological examination. All the control patients underwent knee radiography and US. We excluded patients with evidence of CC on US or radiography and with gout and/or other inflammatory rheumatic diseases. Patients with soft-tissue rheumatism and mild degenerative changes were accepted as controls.

Information about age, gender, weight, and height was collected for all patients. Weight and height were used to calculate the body mass in$\operatorname{dex}(\mathrm{BMI})\left(\mathrm{kg} / \mathrm{m}^{2}\right)$. In addition, patients' self-reported information about smoking status, hypertension, diabetes, diuretics use, meniscectomy, joint trauma, alcohol consumption, and renal lithiasis were recorded.

\section{Laboratory measurements}

Erythrocyte sedimentation rate $(\mathrm{ESR}, \mathrm{mm} / \mathrm{h})$, $\mathrm{C}$ reactive protein (CRP, mg/dl), uric acid $(\mathrm{mg} /$ $\mathrm{dl})$, total calcium ( $\mathrm{mg} / \mathrm{dl})$, ionized calcium $(\mathrm{mg} /$ $\mathrm{dl}$ ), alkaline phosphatase (U/I), magnesium (mg/ $\mathrm{dl})$, and iron $(\mu \mathrm{g} / \mathrm{dl})$ levels were assessed in all patients.

The bone markers-OC (ng/ml), OPG (pmol/ $\mathrm{ml})$, and $\beta$-CTx $(\mathrm{pg} / \mathrm{ml})$ - were measured using enzyme-linked immunosorbent assay kits (BioVendor LM, Czech Republic, for OC and OPG and MyBiosource, USA, for $\beta-C T x)$ in accordance with the manufacturer's instructions. All measurements were performed on the same microplate reader (Tecan Sunrise, Switzerland).

\section{Bone mineral density assessment}

The spine and hip BMD was measured by dual-energy X-ray absorptiometry (DXA) with Lunar DPX ${ }^{\mathrm{TM}}-\mathrm{Pro} / \mathrm{NT}$. The posteroanterior lumbar spine (L2-L4) and the left femoral neck and trochanter were analyzed. BMD was given as $\mathrm{g} / \mathrm{cm}^{2}$ and as T-score values. Osteoporosis was defined as a T-score value of less than -2.5 (25).

\section{Abdominal aortic calcification assessment}

Vascular calcification - that is, AAC-was assessed by lateral radiographs of the lumbar spine (L1-L4), using the anteroposterior severity score (0-24). The scores of the anterior and posterior of each aortic segment were summed up. Calcific deposits were graded from 0 to 3 , as follows: 0 (no aortic calcific deposits), 1 (small scattered calcific deposits occupying less than $1 / 3$ of the longitudinal wall of the aorta), $2(1 / 3-2 / 3$ of the longitudinal wall of the aorta), and 3 ( $\geq 2 / 3$ of the longitudinal wall of the aorta) (26).

\section{Statistical analysis}

Statistical analysis was performed using MedCalc Statistical Software version 18.2.1 (MedCalc Software bvba, Ostend, Belgium; http:// www.medcalc.org; 2018). Quantitative data were expressed as mean \pm standard deviation or median and interquartile range, depending on the normality of the distribution as verified with a Kolmogorov-Smirnov test. Qualitative variables were characterized by frequency and percentage. Differences between groups for quantitative variables were assessed with a Student t-test or a Mann-Whitney test, whichever was appropriate. The differences in frequency were checked using a chi-square test. We used the receiver operating characteristic (ROC) curves for calculating the discriminative value of the bone turnover markers for the diagnosis of CC. Cut-off values were chosen where sensitivity and specificity were at 
their maximum. A two-tailed p-value of less than 0.05 was considered statistically significant.

\section{Results}

The study included $n=73$ patients: $n=36$ patients with $\mathrm{CC}$ and $\mathrm{n}=37$ controls, similar in age and gender. The general characteristics of the enrolled patients are detailed in Table 1.

We found higher levels of serum OC, OPG, and $\beta$-CTx in the CC group than in the controls, as shown in Table 2.

The BMD at the femoral neck, trochanter, and spine was lower in patients with CC than in the controls, but this difference was not statistically significant (Table 2).
As expected, the AAC score was higher in patients with $\mathrm{CC}$ (Table 2) than in the controls. $\mathrm{AAC}$ was present in $38.8 \%$ of the patients with $\mathrm{CC}$ and in $11.1 \%$ of the controls.

Also, the ROC curves of OC, OPG, and $\beta$-CTx were obtained to assess the potential usefulness of the bone turnover markers for the diagnosis of CC. The larger the area under the curve (AUC), the greater the accuracy of the diagnosis (Table 3).

When we compared the serum levels of the bone turnover markers in patients with $\mathrm{CC}$ and osteoporosis to patients with $\mathrm{CC}$ without osteoporosis, only OPG was found to be significantly higher in patients with osteoporosis when BMD was measured in all three sites (trochanter,

Table 1. General characteristics of study participants

\begin{tabular}{|c|c|c|c|}
\hline Variable & $\begin{array}{c}\begin{array}{c}\text { Controls } \\
\mathrm{n}=37\end{array} \\
\end{array}$ & $\begin{array}{c}\begin{array}{c}\text { Chondrocalcinosis } \\
\mathrm{n}=36\end{array} \\
\end{array}$ & $\mathbf{P}$ \\
\hline Age (years) & $\overline{59.8 \pm 9.2}$ & $62.3 \pm 9.8$ & 0.2 \\
\hline \multirow{3}{*}{$\frac{\text { Gender }}{\text { BMI }\left(\mathrm{kg} / \mathrm{m}^{2}\right)}$} & $29(78.4 \%)$ & $25(69.4 \%)$ & \multirow[b]{2}{*}{0.5} \\
\hline & $8(21.6 \%)$ & $11(30.6 \%)$ & \\
\hline & $29.1 \pm 4.9$ & $27.7 \pm 5$ & 0.2 \\
\hline ESR $(\mathrm{mm} / \mathrm{h})$ & $12(8.5-14.5)$ & $11.5(5-31.7)$ & 0.2 \\
\hline CRP $(\mathrm{mg} / \mathrm{dl})$ & $0.5(0.2-0.9)$ & $0.5(0.3-1.4)$ & 0.2 \\
\hline Uric acid $(\mathrm{mg} / \mathrm{dl})$ & $4(3.0-4.5)$ & $4(3.7-5.9)$ & 0.06 \\
\hline Total calcium $(\mathrm{mg} / \mathrm{dl})$ & $8.2(8-9)$ & $9(8-9.4)$ & 0.06 \\
\hline Ionized calcium $(\mathrm{mg} / \mathrm{dl})$ & $4(3.5-4)$ & $4(3.9-4.4)$ & 0.01 \\
\hline Alkaline phosphatase (U/I) & $79(69.5-120)$ & $127(77.7-162.2)$ & 0.003 \\
\hline Magnesium $(\mathrm{mg} / \mathrm{dl})$ & $2(2-2.3)$ & $2(1.9-2.2)$ & 0.2 \\
\hline Iron $(\mu \mathrm{g} / \mathrm{dl})$ & $78(66.5-87.5)$ & $74(59.5-87.7)$ & 0.9 \\
\hline Hypertension $^{1}$ & $2(5.4 \%)$ & $8(22.22 \%)$ & 0.0002 \\
\hline Diabetes $^{1}$ & $0(0 \%)$ & $6(16.6 \%)$ & 0.0005 \\
\hline Hypothyroidism & $0(0 \%)$ & $4(11.11 \%)$ & 0.1 \\
\hline Smoking & $3(8.1 \%)$ & $0(0 \%)$ & 0.2 \\
\hline Diuretics use & $1(2.7 \%)$ & $7(19.4)$ & 0.02 \\
\hline Meniscectomy & $0(0 \%)$ & $1(2.7 \%)$ & 0.4 \\
\hline Joint trauma & $0(0 \%)$ & $1(2.7 \%)$ & 0.4 \\
\hline Alcohol consumption & $0(0 \%)$ & $0(0 \%)$ & 1 \\
\hline Renal lithiasis & $0(0 \%)$ & $1(2.7 \%)$ & 0.4 \\
\hline
\end{tabular}

Quantitative variables are expressed as mean \pm standard deviation or as median and interquartile range); BMI, body mass index; ESR, erythrocyte sedimentation rate; CRP, C reactive protein. ${ }^{1}$ Four of the patients had both hypertension and diabetes 
Table 2. Comparison of bone turnover markers, bone mineral density and abdominal aortic calcification score

\begin{tabular}{lccc}
\hline Variable & $\begin{array}{c}\text { Controls } \\
\mathbf{n}=\mathbf{3 7}\end{array}$ & $\begin{array}{c}\text { Chondrocalcinosis } \\
\mathbf{n}=\mathbf{3 6}\end{array}$ & P \\
\hline OC $(\mathrm{ng} / \mathrm{ml})$ & $4.5(2.6-7.2)$ & $6.5(3.5-9.9)$ & 0.05 \\
\hline OPG $(\mathrm{pmol} / \mathrm{ml})$ & $6.5(5.5-8.12)$ & $7.7(6.2-9.4)$ & 0.02 \\
\hline$\beta$-CTx $(\mathrm{pg} / \mathrm{ml})$ & $5851(5465-6109)$ & $6078(5870-6171)$ & 0.02 \\
\hline Trochanter BMD & $0.2 \pm 1.2$ & $-0.4 \pm 1.5$ & 0.1 \\
\hline Femoral neck BMD & $0.2 \pm 1.3$ & $-0.2 \pm 1.5$ & 0.1 \\
\hline Lumbar spine BMD & $0.7 \pm 2$ & $-0.4 \pm 2$ & 0.2 \\
\hline AAC score & $0.5 \pm 2$ & $3.6 \pm 6.2$ & 0.006 \\
\hline OCC,
\end{tabular}

OC, osteocalcin; OPG, osteoprotegerin; $\beta$-CTx, Beta CrossLaps; BMD, bone mineral density; AAC, abdominal aortic calcification. BMD values are expressed as $\mathrm{T}$ score

Table 3. The ROC curves analysis: assessment of the discriminative values for bone turnover markers in chondrocalcinosis

\begin{tabular}{cccccc}
\hline & $\begin{array}{c}\text { Cut-off } \\
\text { values }\end{array}$ & AUC & Sensitivity & Specificity & \multirow{2}{*}{ P } \\
\hline \multirow{2}{*}{ OC } & 6.1 & 0.634 & $52.7 \%$ & $72.9 \%$ & \\
& $\mathrm{ng} / \mathrm{ml}$ & $(95 \% \mathrm{CI}$, & $(95 \% \mathrm{CI}$, & $(95 \% \mathrm{CI}$, & 0.04 \\
& & $0.513-0.743)$ & $35.5 \%-69.6 \%)$ & $55.9 \%-86.2 \%)$ & \\
\hline \multirow{3}{*}{ OPG } & $7.3 \mathrm{pmol} /$ & 0.651 & $61.1 \%$ & $70.2 \%$ & \\
& $\mathrm{ml}$ & $(95 \% \mathrm{CI}$, & $(95 \% \mathrm{CI}$, & $(95 \% \mathrm{CI}$, & 0.02 \\
& & $0.530-0.759)$ & $43.5 \%-76.9 \%)$ & $53 \%-84.1 \%)$ & \\
\hline \multirow{3}{*}{$\beta-$-CTx } & $5851 \mathrm{pg} / \mathrm{ml}$ & $(95 \% \mathrm{CI}$, & $77.7 \%$ & $56.7 \%$ & \\
& & $0.537-0.764)$ & $60.8 \%-89.9 \%)$ & $39.5 \%-72.9 \%)$ & \\
\hline
\end{tabular}

OC, osteocalcin; OPG, osteoprotegerin; $\beta$-CTx, $\beta$ CrossLaps; AUC, area under the curve, CI, confidence interval.

femoral neck, and lumbar spine) and only $\mathrm{OC}$ when BMD was measured at the trochanter, as summarized in Table 4. We did not find any differences in the control group between patients with and without osteoporosis. The correlation between the three bone turnover markers and different clinical, demographic, or laboratory parameters were also assessed in $\mathrm{CC}$ patients; the results are detailed in Table 5. In brief, OC was negatively correlated with BMI; OPG was positively correlated with age, alkaline phosphatase, creatinine, and AAC score; and $\beta-C T x$ did not correlate with any of the parameters. OPG was not correlated with $\mathrm{AAC}$ in patients without $\mathrm{CC}$ $(1.04, \mathrm{p}=0.06)$.

\section{Discussion}

The study has investigated the modification of serum OC, OPG, and $\beta$-CTx levels, as well as the potential association with BMD and $\mathrm{AAC}$, in patients with CC.

The rationale of the study started from the potential links between bone status, vascular calcification, and articular calcification beyond the aging process. 
Table 4. Bone turnover markers in patients with chondrocalcinosis according with $T$ score

\begin{tabular}{|c|c|c|c|}
\hline Variable & T score $\geq-2.5$ & T score $<-2.5$ & $\mathbf{P}$ \\
\hline \multicolumn{4}{|c|}{ Trochanter BMD } \\
\hline & $\mathrm{n}=30$ & $n=6$ & \\
\hline $\mathrm{OC}(\mathrm{ng} / \mathrm{ml})$ & $4.9(2.74-8)$ & $6.1(5.3-12)$ & 0.03 \\
\hline OPG (pmol/ml) & $6.9(5.8-8.54)$ & $9.3(7.6-9.5)$ & 0.01 \\
\hline$\beta$-CTx $(\mathrm{pg} / \mathrm{ml})$ & $5977(5780-6150)$ & $6027(5637-6248)$ & 0.7 \\
\hline \multicolumn{4}{|c|}{${ }_{n=32}$ Femoral neck BMD } \\
\hline & $n=32$ & $n=4$ & \\
\hline $\mathrm{OC}(\mathrm{ng} / \mathrm{ml})$ & $5.07(2.8-8.2)$ & $5.5(3.4-15.3)$ & 0.3 \\
\hline OPG (pmol/ml) & $6.9(5.8-8.4)$ & $9.4(8.8-10.7)$ & 0.01 \\
\hline$\beta$-CTx $(\mathrm{pg} / \mathrm{ml})$ & $5987(5794-6150)$ & $5949(5645-6393)$ & 0.7 \\
\hline \multicolumn{4}{|c|}{ Lumbar spine BMD } \\
\hline & $\mathrm{n}=27$ & $\mathrm{n}=9$ & \\
\hline $\mathrm{OC}(\mathrm{ng} / \mathrm{ml})$ & $4.9(2.74-8.19)$ & $5.7(3.6-9.33)$ & 0.2 \\
\hline OPG (pmol/ml) & $6.7(5.7-8.26)$ & $9.3(7-9.5)$ & 0.003 \\
\hline$\beta-\mathrm{CTx}(\mathrm{pg} / \mathrm{ml})$ & 6007 (5794-6150) & $5870(5571-6193)$ & 0.6 \\
\hline
\end{tabular}

OC, osteocalcin; OPG, osteoprotegerin; $\beta$-CTx, Beta CrossLaps; BMD, bone mineral density.

Table 5. The correlations of bone turnover markers in patients with chondrocalcinosis

\begin{tabular}{lll}
\hline Variable & & r value (p value) \\
\hline OC & BMI & $-0.4(\mathrm{p}<0.001)$ \\
\hline \multirow{3}{*}{ OPG } & Age & $0.5(\mathrm{p}<0.001)$ \\
\cline { 2 - 3 } & Alkaline phosphatase & $0.2(\mathrm{p}=0.03)$ \\
\cline { 2 - 3 } & Creatinine & $0.3(\mathrm{p}<0.001)$ \\
\cline { 2 - 3 } & AAC & $0.278(\mathrm{p}=0.01)$ \\
\hline
\end{tabular}

OC, osteocalcin; OPG, osteoprotegerin; BMI, body mass index; AAC, abdominal aortic calcification.

Calcium phosphate mineralization necessary for bone matrix formation is inhibited by PPi, but other factors are also involved in this complex interplay, such as alteration in vitamin $\mathrm{D}$ and $\mathrm{K}$ metabolism, matrix metalloproteinases, collagen cleavage, genetic polymorphisms of enzymes including human ankylosis, tumor growth factor beta, vitamin K-dependent carboxylation/gamma-carboxyglutamic domain (matrix Gla protein), bone morphogenic protein-7, adenosine triphosphate binding cassette transporter subtype (6), osteopontin, OPG, and low-grade inflammation (10-15). Addison et al. found that PPi inhibits the mineralization of osteoblast cultures through different mechanisms (16). Also, CPP crystals stimulate osteoclastogenesis through receptor activation of nuclear factor kappa- $\beta$ ligand (RANKL), p38 mitogen-activated protein kinase, and extracellular-signal-regulated kinase. These lead to local bone resorption (1719). Moreover, OPG knock-out mice developed osteoporosis and calcifications (20). Abhishek et al. suggest a generalized predisposition of CPPD (21).

Common mechanisms of arterial and articular calcification are aging, inorganic phosphate, altered differentiation of VSMC and chondrocytes, a deficiency of calcification inhibitors 
(mainly PPi), low-grade inflammation, and the pro-mineralizing effect of apoptosis and matrix vesicles $(14,15)$. Also, OPG/RANKL, leptin, and excess of inorganic phosphate are involved in arterial calcification, while an excess of PPi and upregulated transglutaminases are inhibitors of cartilage calcification. In $\mathrm{CC}$, besides the above-mentioned mechanism, chondrocyte hypertrophy and the capacity of chondrocytes to produce high amounts of PPi are also involved $(7,14,15)$. OC and alkaline phosphatase are described as calcification promoters and low OPG as a calcification inhibitor (27).

There are no published studies on serum levels of these three bone markers in $\mathrm{CC}$, and only a few studies analyzed the association between CC and BMD $(28,29)$.

Furthermore, the association between BMD and vascular calcification in patients with $\mathrm{CC}$ was assessed only by the presence or absence of calcification, not by a scoring system (28).

Regarding BMD, in our study, the hip and spine BMD was lower in patients with CC than in the controls, but this difference was not statistically significant. Also, the percentage of patients with osteoporosis was higher in the CC group than in the control group. It is important to mention that osteoarthritis of the spine and large joints can interfere with spine and hip DXA examination because of increased BMD (30-33). In a large study, the BMD was examined by the metacarpal index and calcaneal DXA but not by hip and lumbar spine DXA, which are the gold standard. The authors found an association between a low metacarpal index and CC but not with calcaneal DXA (28). Other authors found an association between higher BMD and knee CC (30). An explanation for the association with cortical BMD, but not with trabecular BMD, might be the high levels of parathyroid hormone 44-68 peptide in the patients with CPPD, although this fragment is not known to have an effect on bone metabo$\operatorname{lism}(34,35)$.
In our study, serum levels of OC, OPG, and $\beta$-CTx were higher in patients with $\mathrm{CC}$ than in age- and gender-matched control subjects. We also found significantly higher alkaline phosphatase levels in the CC group, but these were within the reference intervals.

In $\mathrm{CC}$, the only bone turnover marker examined in other studies was urinary CrossLaps and bone alkaline phosphatase, which were not significantly altered compared to the control population (36).

There are a few studies that demonstrated that serum levels of OC, OPG, and $\beta-\mathrm{CT}$ x are higher in patients with low BMD (37-39). The proven association between higher bone turnover markers and lower BMD was confirmed in our study only by OPG at all measured sites and by OC measured at the trochanter.

Our observations suggest that bone turnover markers can provide information about bone status before the DXA alteration in patients with $\mathrm{CC}$, due to the known association between $\mathrm{CC} /$ osteoarthritis and interference with BMD.

We also calculated the discriminative value of the bone turnover markers for the diagnosis of CC. Our analysis of ROC curves indicated that the studied markers have poor diagnostic accuracy for $\mathrm{CC}$.

The only bone turnover marker associated with osteoporosis in patients with CC was OPG. Also, OPG was positively correlated with AAC in the same group of patients. The relationship between OPG and BMD in different pathological states is still under debate. In a genetic study, ablation of the OPG gene by targeted gene deletion in mice was associated with osteoporosis and arterial calcification (20). In contrast, high levels of OPG were associated with lower BMD, acting as a calcification inhibitor $(27,38)$. The same controversy surrounds OPG and vascular disease. In a genetic study, OPG knock-out mice developed arterial calcifications, while in a clinical study, high levels of OPG were associated with vascu- 
lar calcification (20). Therefore, the high OPG serum levels found in our patients with CC suggest that OPG could be a marker for bone loss and AAC. In agreement with other studies, we found an association between vascular calcification and $\mathrm{CC}(13,28)$. Patients with $\mathrm{CC}$ had higher AAC scores than the age- and gender-matched controls. To our knowledge, this is the first study to evaluate $\mathrm{AAC}$ in patients with $\mathrm{CC}$ according to a scoring system.

Nevertheless, there were several limitations to our study. We did not evaluate the complete extent of the vascular calcification by performing whole-body computed tomography. We could not establish a cause-effect relationship between the levels of circulating OC, OPG, and $\beta-\mathrm{CTx}$ and BMD or AAC due to the cross-sectional design of the study, as well as the small number of investigated patients.

In the future, we will try to investigate the relationship between bone turnover markers and oxidative stress in risk populations and the association with other calcification markers, such as matrix Gla protein (40). Although this was a pilot study, the outcomes could provide an incentive for further studies on bone status reflected by modified serum markers or even in the synovial fluid of patients with $\mathrm{CC}$.

Bone turnover markers could be valuable for bone status assessment in patients with $\mathrm{CC}$. Moreover, in these patients, serum bone markers could fluctuate earlier than BMD modification.

\section{Conclusions}

Higher serum values of $\mathrm{OC}, \mathrm{OPG}$, and $\beta-\mathrm{CTx}$ were found in patients with $\mathrm{CC}$ than in controls represented by patients with mechanical pain. Higher serum levels of OPG were associated with both osteoporosis and AAC. The presence of AAC was more common in patients with $\mathrm{CC}$ who also had higher ACC scores than in the ageand gender-matched controls. As a hypothesis that should be further proven, we propose that higher serum levels of OPG might be an indicator for the presence of aortic calcifications in patients with $\mathrm{CC}$.

\author{
Abreviations \\ CC - chondrocalcinosis \\ CPP - calcium pyrophosphate \\ US - ultrasound \\ PPi - inorganic pyrophosphate \\ $\mathrm{BCP}$ - basic calcium phosphate \\ VSMC - vascular smooth muscle cell \\ BMD - bone mineral density \\ OC - osteocalcin \\ OPG - osteoprotegerin \\ $\beta$-CTx - beta CrossLaps \\ CPPD - calcium pyrophosphate deposition \\ AAC - abdominal aortic calcification \\ BMI - body mass index \\ ESR - erythrocyte sedimentation rate \\ CRP - C reactive protein \\ DXA - dual-energy X-ray absorptiometry \\ ROC - receiver operating characteristic \\ AUC - area under the curve \\ Matrix Gla protein vitamin K-dependent carbox- \\ ylation/gamma-carboxyglutamic domain \\ RANKL - receptor activator of nuclear factor \\ kappa- $\beta$ ligand
}

\section{Acknowledgments}

This study was supported by the project no.7690/34/14.04.2016, granted by the University of Medicine and Pharmacy "Iuliu Haţieganu" Cluj-Napoca

\section{Author's contribution}

PV-conceptualization, investigation, methodology, writing-original draft preparation. CS-resources, writing-original draft preparation. LD-investigation, resources. SSP-investigation, resour- 
ces. AC-resources. SR-investigation, resources, supervision.

\section{Conflict of interest}

The authors declare no conflict of interest.

\section{References}

1. McCarty DJ. Calcium pyrophosphate dihydrate (CPPD) crystal deposition disease - nomenclature and diagnostic criteria. Ann Int Med. 1977 Aug; 87:240-242. DOI: 10.7326/0003-4819-87-2-240

2. Zhang W, Doherty M, Bardin T, Barskova V, Guerne PA, Jansen TL et al. European league against rheumatism recommendations for calcium pyrophosphate deposition. Part I: Terminology and diagnosis. Ann Rheum Dis. 2011 Apr;70(4):563-570. DOI: 10.1136/ ard.2010.139105

3. Genant HK Roentgenographic aspects of calcium. pyrophosphate dihydrate crystal deposition disease (pseudogout). Arthritis Rheum. 1976 May-Jun;19 (Suppl 3):307-28. DOI: 10.1002/1529-0131(197605/06)19:3+<307::AIDART1780190705>3.0.CO;2-9

4. Frediani B, Filippou G, Falsetti P, Lorenzini S, Baldi F, Acciai C et al. Diagnosis of calcium pyrophosphate dihydrate crystal deposition disease: Ultrasonographic criteria proposed. Ann Rheum Dis. 2005 Apr;64(4): 638-640. DOI: 10.1136/ard.2004.024109

5. Thouverey C, Bechkoff G, Pikula S, Buchet R. Inorganic pyrophosphate as a regulator of hydroxyapatite or calcium pyrophosphate dihydrate mineral deposition by matrix vesicles. Osteoarthr Cartil. 2009 Jan;17(1):6472. DOI: $10.1016 /$ j.joca.2008.05.020

6. Terkeltaub RA. What does cartilage calcification tell us about osteoarthritis? Journal of Rheumatology. 2002 Apr;29(3):411-5.

7. Wilson PW, Kauppila LI, O’Donnel CJ, Kiel DP, Hannan M, Polak JM et al. Abdominal aortic calcific deposits are an important predictor of vascular morbidity and mortality. Circulation. 2001 Mar;103(11):1529-1534. DOI: 10.1161/01.CIR.103.11.1529

8. Hofbauer LC, Schoppet M. Clinical implications of the osteoprotegerin/RANKL/RANK system for bone and vascular diseases. JAMA. 2004 Jul;28;292(4):490-495. DOI: $10.1001 /$ jama.292.4.490

9. Von der Recke P, Hansen MA, Hassager C. The association between low bone mass at the menopause and cardiovascular mortality. Am J Med. 1999 Mar;106(3):2738. DOI: 10.1016/S0002-9343(99)00028-5

10. Rutsch F, Nitschke Y,Terkeltaub R. Genetics in arterial calcification: Pieces of a puzzle and cogs in a wheel. Circ Res. 2011 Aug;109:578-592. DOI: 10.1161/CIR-

\section{CRESAHA.111.247965}

11. Cailotto F, Bianchi A, Sebillaud S, Venkatesan N, Moulin D, Jouzeau JY et al. Inorganic pyrophosphate generation by transforming growth factor-beta-1 is mainly dependent on ANK induction by Ras/Raf-1/extracellular signal-regulated kinase pathways in chondrocytes. Arthritis Res Ther. 2007;9(6):R12. DOI: 10.1186/ ar2330

12. Wu M, Rementer C, Giachelli CM. Vascular calcification: An update on mechanisms and challenges in treatment. Calcif Tissue Int. 2013 Oct; 93(4):365-373. DOI: 10.1007/s00223-013-9712-z

13. Abhishek A, Doherty S, Maciewicz R, Muir K, Zhang $\mathrm{W}$, Doherty $\mathrm{M}$ et al. The association between ANKH promoter polymorphism and chondrocalcinosis is independent of age and osteoarthritis: Results of a case-control study. Arthritis Res Ther. 2014 Jan;16(1):R25. DOI: 10.1186/ar4453

14. Rutsch F, Terkeltaub R. Parallels between arterial and cartilage calcification: what understanding artery calcification can teach us about chondrocalcinosis. Curr Opin Rheumatol. 2003 May; 15(3):302-310. DOI: 10.1097/00002281-200305000-00019

15. Rutsch F, Terkeltaub R. Deficiencies of physiologic calcification inhibitors and low-grade inflammation in arterial calcification: lessons for cartilage calcification. Joint Bone Spine. 2005 Mar;72(2):110-118. DOI: 10.1016/j.jbspin.2004.05.014

16. Addison WN, Azari F, Sørensen ES, Kaartinen MT, McKee MD. Pyrophosphate inhibits mineralization of osteoblast cultures by binding to mineral, up-regulating osteopontin, and inhibiting alkaline phosphatase activity. J Biol Chem. 2007 May;282(21):15872-83. DOI: 10.1074/jbc.M701116200

17. Chang CC, Tsai YH, Liu Y, Lin SY, Liang YC. Calcium-containing crystals enhance receptor activator of nuclear factor $\mathrm{\kappa B}$ ligand/macrophage colonystimulating factor-mediated osteoclastogenesis via extracellular-signal-regulated kinase and p38 pathways. Rheumatol. 2015 Mar;54(10):1913-22. DOI: 10.1093/rheumatology/kev 107

18. Cheung HS, Sallis JD, Demadis KD, Wierzbicki A. Phosphocitrate blocks calcification-induced articular joint degeneration in a guinea pig model. Arthritis Rheum. 2006 Aug;54(8):2452-61. DOI: 10.1002/ art. 22017

19. McCarthy GM, Dunne A. Calcium crystal deposition diseases - beyond gout. Nat Rev Rheumatol. 2018 Oct;14(10),592-602. DOI: 10.1038/s41584-018-00785

20. Bucay N, Sarosi I, Dunstan CR, Morony S, Tarpley J, Capparelli $\mathrm{C}$ et al. Osteoprotegerin-deficient mice develop early onset osteoporosis and arterial calcification. Genes Dev. 1998 May;12(9):1260-8. DOI: 10.1101/ gad.12.9.1260 
21. Abhishek A, Doherty S, Maciewicz R, Muir K, Zhang W, Doherty M. Evidence of a systemic predisposition to chondrocalcinosis and association between chondrocalcinosis and osteoarthritis at distant joints: A cross-sectional study. Arthritis Care Res (Hoboken). $2013 \mathrm{Jul}$; 65(7):1052-8. DOI: 10.1002/acr.21952

22. Bailey AJ, Mansell JP, Sims TJ, Banse X. Biochemical and mechanical properties of subchondral bone in osteoarthritis. Biorheology. 2004;41(3-4):349-58.

23. Garnero P, Piperno M, Gineyts E, Christgau S, Delmas PD, Vignon E . Cross sectional evaluation of biochemical markers of bone, cartilage, and synovial tissue metabolism in patients with knee osteoarthritis: Relations with disease activity and joint damage. Ann Rheum Dis. 2001 Jun; 60(6):619-26. DOI: 10.1136/ard.60.6.619

24. Swan A, Amer H, Dieppe P. The value of synovial fluid assays in the diagnosis of joint disease: a literature survey. Ann Rheum Dis. 2002 Jun;61(6):493-8. DOI: 10.1136/ard.61.6.493

25. Kanis JA. An update on the diagnosis of osteoporosis. Current Rheumatol Rep. 2002 Feb;2(1): 62-66. DOI: 10.1007/s11926-996-0070-y

26. Kauppila LI, Polak JF, Cupples LA, Hannan MT, Kiel DP, Wilson PW. New indices to classify location, severity and progression of calcific lesions in the abdominal aorta: A 25-year follow-up study. Atherosclerosis. 1997 Jul;132(2): 245-250. DOI: 10.1016/S00219150(97)00106-8

27. Cannata-Andia JB, Roman-Garcia P, Hruska K . The connections between vascular calcification and bone health. Nephrol Dial Transplant. 2011 Nov; 26(11):3429-3436 DOI: 10.1093/ndt/gfr591

28. Doherty M. Association between low cortical bone mineral density, soft-tissue calcification, vascular calcification and chondrocalcinosis: a case-control study. Ann Rheum Dis. 2014 Nov;73(11):1997-2002. DOI: 10.1136/annrheumdis-2013-203400

29. Kleiber Balderrama C, Rosenthal AK, Lans D, Singh JA, Bartels CM. Calcium pyrophosphate deposition disease and associated medical comorbidities: A national cross-sectional study of us veterans. Arthritis Care Res (Hoboken). 2017 Sep; 69(9):1400-1406. DOI: $10.1002 /$ acr. 23160

30. Hardcastle SA, Dieppe P, Gregson CL, Arden NK, Spector TD, Hart DJ, Edwards $\mathrm{MH}$ et al. Individuals with high bone mass have an increased prevalence of radiographic knee osteoarthritis. Bone. 2015 Feb;
71:171-9. DOI: 10.1016/j.bone.2014.10.015

31. Neame RL, Carr AJ, Muir K, Doherty M. UK community prevalence of knee chondrocalcinosis: Evidence that correlation with osteoarthritis is through a shared association with osteophyte. Ann Rheum Dis. 2003 Jun;62(6):513-518. DOI: 10.1136/ard.62.6.513

32. Garg MK, Kharb S. Dual energy X-ray absorptiometry: Pitfalls in measurement and interpretation of bone mineral density. Indian J Endocrinol Metab. 2013 Mar; 17(2),203-10 DOI: 10.4103/2230-8210.109659

33. Ichchou L, Allali F, Rostom S, Bennani L, Hmamouchi I, Abourazzak FZ et al. Relationship between spine osteoarthritis, bone mineral density and bone turn over markers in post menopausal women. BMC Womens Health. 2010 Aug;10:25. DOI: 10.1186/1472-6874-1025

34. Pawlotsky Y, Massart C, Guggenbuhl P, Albert JD, Perdriger A, Meadeb Jet al. Elevated parathyroid hormone 44-68 in idiopathic calcium pyrophosphate dihydrate crystal deposition disease. Role of menopause and iron metabolism? J Rheumatol 2008 Feb;35(2):315-318.

35. Mosekilde L. Primary hyperparathyroidism and the skeleton. Clin Endocrinol (Oxf). 2008 Jul;69(1):1-19. DOI: $10.1111 / \mathrm{j} .1365-2265.2007 .03162 . \mathrm{x}$

36. Ramonda R, Musacchio E, Perissinotto E, Sartori L, Punzi L, Corti MC et al. Prevalence of chondrocalcinosis in Italian subjects from northeastern Italy. The Pro. V. A. (PROgetto Veneto Anziani) study. Clin Exp Rheumatol. 2009 Nov-Dec;27(6):981-4.

37. Singh S, Kumar D, Lal AK. Serum osteocalcin as a diagnostic biomarker for primary osteoporosis in women. J Clin Diagnostic Res. 2015 Aug; 9(8):RC04-RC07. DOI: $10.7860 / J C D R / 2015 / 14857.6318$

38. Jabbar S, Drury J, Fordham JN, Datta HK, Francis RM, Tuck SP. Osteoprotegerin, RANKL and bone turnover in postmenopausal osteoporosis. J Clin Pathol. 2011 Apr;64(4):354-357. DOI: 10.1136/jcp.2010.086595

39. Kawana K, Takahashi M, Hoshino H, Kushida K. Comparison of serum and urinary C-terminal telopeptide of type I collagen in aging, menopause and osteoporosis. Clin Chim Acta. 2012 Feb;316(1-2):109-115. DOI: 10.1016/S0009-8981(01)00742-2

40. Sandor R, Leucuta D, Dronca E, Niculae A, Cret V, Silaghi $\mathrm{C}$ et al. Low Serum Paraoxonase-1 Lactonase and Arylesterase Activities in Obese Children and Adolescents. Rev Romana Med Lab. 2015 Dec;23(4):385-95. DOI: $10.1515 / \mathrm{rrlm}-2015-0038$ 